\title{
Thoughts on Personnel Management of Disease Control Departments after Public Health Emergencies Based on the Perspective of Human Resource Management
}

\author{
Yang Yang, Keming Liao, Ergu DiRe \\ Southwest Minzu University, Chengdu, China \\ Email: 1047127006@qq.com
}

How to cite this paper: Yang, Y., Liao, K. and DiRe, E. (2021) Thoughts on Personnel Management of Disease Control Departments after Public Health Emergencies Based on the Perspective of Human Resource Management. Open Access Library Journal, 8: e7763. https://doi.org/10.4236/oalib.1107763

Received: July 15, 2021

Accepted: August 6, 2021

Published: August 9, 2021

Copyright $\odot 2021$ by author(s) and Open Access Library Inc.

This work is licensed under the Creative Commons Attribution International License (CC BY 4.0).

http://creativecommons.org/licenses/by/4.0/

\section{(c) (i) Open Access}

\begin{abstract}
In COVID-19 outbreak, such a sudden public health incident, the deficiency of China's department of CDC exposed, especially the disease control department's ability to cope with risk is low. For public health emergency department personnel management, it is a wake-up call for disease control. Starting from the current situation of personnel management in the disease control department, from the perspective of human resources management, this paper discusses how to improve the management of personnel to improve the capacity of the disease control department to respond to public health emergencies, and puts forward relevant suggestions and measures.
\end{abstract}

\section{Subject Areas \\ Public Policy Analysis}

\section{Keywords}

Human Resources, For Disease Control Department, Personnel Management, Public Health Emergency

\section{The Related Literature Review}

After the outbreak of new coronary pneumonia, a national public health event, the management of personnel in the disease control department has brought new challenges and requirements, but how to improve and how to manage, so far are still in further research. This paper, starting from the perspective of human resource management, in public health events after such public welfare in- 
stitutions for disease control department staff management issues, provides suggestions to promote the development of the department for disease control.

After consulting the relevant information and literature, the relevant literature of the research on the management of personnel in the disease control department was classified:

\subsection{For Disease Control and Prevention Department of the Construction of Talent Team}

For CDC department personnel development and construction, it is currently one of the major research directions. Professor Huang Yiping believes that it is necessary to do a good job in adjusting the personnel of the disease control department and providing talents with room to develop their talents, and in his article, he mentioned that "perfecting the system of disease prevention and control and strengthening the personnel construction of the public health team" [1].

Huang Jiatian, professor of the status quo of the construction of the modern CDC talent team and innovation, put forward views on deepening the reform of personnel system and management system. A more detailed study of the talent demand of China's disease control institutions is carried out, and it is considered that the current not only should we expand the scale of the talent team, but also start with the individual quality and scientific research ability, and enhance the innovation of the talent team construction [2].

\subsection{CDC Research Department Personnel Appointment}

Some scholars believe that the current disease prevention, control and public health emergency response work in the disease control department is paid more and more attention and supported by the government. On this basis, the cause of disease control prevention and control should be more standardized and efficient; the need to further improve the recruitment of personnel, such as some staff on the job is not in the establishment of the problem, as well as the scientific setting of the post and the number of personnel matching the problem [3]. It is proposed that in the process of personnel appointment, the post setting should match the existing personnel size, and prevent the position from being set unreasonably and affecting the promotion conditions and opportunities of new recruits.

\subsection{CDC Research Department Personnel Treatment}

"Continue to increase investment in public health and improve professional response capacity," said Professor Chen Qiuxuan in his article "Continuing to Deepen Structural Reforms on the Supply Side of Public Health". This includes the disease control department staff treatment problems, money problems, and the enthusiasm of the staff. On the current situation and countermeasure of the compensation system of the disease control institutions, this paper analyzes the current situation of the salary of the personnel of the disease control department 
in our country, and thinks that the difference between the current job responsibilities and the performance reward mechanism is small, which is not conducive to stimulating the enthusiasm of the personnel. This paper puts forward the idea of refining the individual's salary treatment according to the person's post responsibility, and starting from the general direction of perfecting the performance reward, and putting forward the view that the individual's work performance is more closely related to the welfare and treatment [4].

\section{For Disease Control and the Present Situation of the Personnel Management}

\subsection{For Disease Control and Prevention Department Prepare the Status Quo}

According to the Guidelines on the Establishment standards of the CDC's institutions issued by the Office of the Central Organization Preparation Committee in 2014, the internal institutions of the CDC are mainly divided into operational institutions and comprehensive management bodies such as party and government, logistics and so on. The number of operational agencies is required to account for 70 per cent of the total number of internal institutions and 30 per cent for integrated management bodies [5].

Staffing is approved in principle in accordance with the ratio of 1.75 per 10,000 of the resident population of each place, and among the staff staffing of the disease control departments, the relevant technical personnel are required to account for 85 per cent of the total establishment and health technicians are required to be higher than 70 per cent. Take Sichuan Province as an example to consult relevant information, according to Sichuan Province in 2013-2018 to declare the provincial assessment of the disease control department, the average number of provincial and municipal disease control agencies is 109 people, compared with 54 people at the county level.

\subsection{For Disease Control and Prevention Department of Posts Set the Status Quo}

Post setting structure is divided into two main categories:

There are three types of job categories, and management positions are mainly responsible for the day-to-day leadership and management responsibilities of the CDC. Professional and technical posts focus on strong professional and technical work. Those logistics skills, according to the regulations of the state are divided into a special type of work, general type of work and the general type of work.

Post level settings, divided into five levels, one is the management position level, for four levels, that is, the regular section level, deputy section level, section staff, clerks. Second, professional and technical post level, is mainly divided into 10 levels, including high, middle and junior. Three is the main series of professional and technical posts, including doctors, technicians, etc. Four is a body 
specialized technical posts, accounting for $22 \%$ of all jobs. Five is to support skill level, including technical and ordinary job.

\subsection{For Disease Control and Prevention Department Personnel Salary Status}

According to the division, department of CDC around development degree is different, department personnel income for disease control in the coastal area is higher than that of inland revenue in some parts of the CDC departments. The disease control department does not have a differentiated incentive mechanism in the job distribution system, in different positions, regardless of the size of the workload and the quality of work, the difference in personnel treatment is not large. In the disease control department, the implementation of basic performance pay accounted for $70 \%$, incentive performance pay accounted for $30 \%$, incentive performance including performance assessment awards, labor discipline awards.

\section{For Disease Control and Prevention Department Personnel Management Problems}

\subsection{Questions about Personnel Structure Rationality}

- Age structure. In the current setting of the disease control department, there is a certain age structure unreasonable phenomenon, mainly in the disease control department institutions with deeper qualifications of workers older, and the new personnel involved in the work are mostly young people, lack of work experience. To a certain extent, making the institutions for disease control and prevention department internal personnel on age structure differentiation is serious [6].

- Degree structure. Now, there is inequality of distribution of talent education; medical education needs to accelerate the homogenization and elite [7]. At present, the training of medical students in major universities is implemented in the " 3 plus 2 " training model, mainly for undergraduate medical students. Therefore, in the disease control department, personnel set up, professional and technical personnel are generally undergraduate education, higher education of technical personnel are relatively lacking.

\subsection{Post Staff Shortage Problem about High Technology}

At present, there are still many problems in the staffing of the disease control departments at the municipal and county levels, and the dynamic management flow of post settings is on the surface, which cannot be carried out in all directions [8]. Especially the current outbreak of COVID-19 such a public health incident, will be a greater demand for high technical post personnel. It also requires professional counterparts to participate in disease prevention and control research. In 2009-2017, the national public health personnel and technical personnel total volume increased by $76.3 \%$ and $80.8 \%$ respectively, but for disease 
control and prevention department of health personnel and technical personnel, decreased by $3.0 \%$ and $4.1 \%$ respectively, at present, the department of CDC staff, about 187,800 people [9].

\subsection{About Compensation for Disease Control and Prevention Department Staff}

The disease control department has not set up a differentiated reward mechanism because of the difficulty of the job, and has not further improved the post compensation mechanism. Because of the particularity of the work of the disease control department, it is difficult to quantify the work, which leads to the dominant subjectivity in performance appraisal, which directly affects the remuneration of staff. Department staff focus on compensation, benefits, do not take the job responsibility. This has led to many high-paying low-energy or high-paying idlers [10].

\section{For Disease Control and Prevention Department Personnel Management Optimization Suggestions}

\subsection{The Reform of Personnel System, Increasing Personnel Equipped with Total}

The current institutional set-up of the disease control department, in the existing employment mechanism, needs to be reformed and innovated to provide a fairer, more open and transparent employment system. On the current lack of highly educated technical personnel in the disease control department, in the recruitment of professional and technical personnel, we should pay more attention to the candidates for professional knowledge, skills of the degree of mastery.

It is recommended that the total staffing of the CDC should be appropriately increased to improve the capacity to deal with public health emergencies. Under the premise of fulfilling the basic functions of disease prevention and control, it is appropriate to absorb certain talents. At the same time, we should do a good job on the agency's posts, responsibilities, from the two aspects of people, responsibilities, and further improve the core strength of the CDC.

\subsection{To Optimize the Management Mode, Strengthening the Construction of Talent Team}

Optimize the management mode of the disease control department and increase the investment in the training of high-level medical personnel. We will accelerate the formation of a high-level health personnel and play their fundamental, global, stable and long-term functions.

The implementation of job classification management and reasonable recruitment, so that posts, employees and work in a reasonable and coordinated operation. Actively establish a new management model in line with the professional characteristics of disease control and prevention, so that more talented people get a good working and living environment, thus forming a new situation 
of coordinated development of personnel training, scientific research and health services.

\subsection{Perfect Compensation Mechanism, Improve the Disease Control Department Staff Enthusiasm}

We will improve the normal wage growth mechanism for employees, improve the guidance system for wage guidance in the human resources market and the information guidance system for labor costs in the industry, speed up the establishment of a standardized system of salary investigation and information dissemination, and provide reference for the rational determination of workers' wages. Scientific analysis of job responsibilities, etc., the standard of performance appraisal is qualitatively quantified, the standard of talent assessment is based on local conditions, different positions should be formulated different treatment system. To improve performance appraisal, we should link wages to performance, and we should adhere to the principles of fairness, fairness, openness and transparency, and associate the results with the promotion of employees. The performance reward is redistributed by the proportion of the coefficients of the comprehensive factors such as responsibility, professional level and job difficulty.

\section{Conclusion}

After a public health emergency, this paper explores and thinks about how to optimize the personnel management of the disease control department from the aspect of human resources. At present, the disease control department's ability to deal with risks is still low, and it needs to focus on repairing the system, personnel structure and personnel capacity. At this stage, only by doing a good job in the management of the personnel of the disease control department and reasonably managing the personnel with scientific countermeasures can we improve the ability of the disease control department to deal with sudden public health events. The author's research only stays on the comprehensive review of the literature, and more field investigations are needed as theoretical support.

\section{Conflicts of Interest}

The authors declare no conflicts of interest.

\section{References}

[1] Huang, Y. (2020) Reflecting on the Epidemic, China's Disease Control Reformed. Chinese Brand, No. 3, 89.

[2] Huang, J. (2020) The Status Quo of the Construction of the Modern CDC Talent Team and Innovation. Talent Development, No. 4, 43-44.

[3] Huang, J. (2019) The CDC Post Arrangement and the Practice Thinking of Personnel Appointment. Office Business, No. 17, 41, 48.

[4] Chen, J. (2019) The Theory of CDC Compensation System Present Situation and the Countermeasures. Modern Business, No. 36, 2. 
[5] Yuan, H., Mao, S., Zhou, J., Luo, W., Chen, J., Zhang, L., Zhou, Q. and Zhang, Y. (2019) Analysis of the Effect of the Creation of the Level of Disease Prevention and Control Institutions in Sichuan Province, 2013-2018. Journal of Preventive Medical Intelligence, 35, 121-125.

[6] Yu, F. (2019) The Functional Positioning of Disease Control Agencies and the Preliminary Exploration of Internal Agency Settings in the New Situation. Public Health Management in China, 17, 2.

[7] Jiang, Y. (2018) The Centers for Disease Control and Post Setting and Personnel Hiring Practices and Thinking. Rural Health, China, No. 1, 30-31.

[8] Cao, G. (2020) The Public Health System Construction on Completion Short Board. Dalian Daily, 2020-03-16(006).

[9] Cai, Y., Meng, C., Ma, Z., Chen, L., Zhang, T., Sun, X. and Wu, H. (2019) The CDC Researchers Pay Satisfaction after Three Fee. Modern Preventive Medicine, 46, 30-35.

[10] Zhan, Q. (2020) The COVID-19 Outbreak Brought Medical Thinking. Guangming Daily, 2020-04-01(007). 